\title{
Contents and quality of travel tips on malaria in English and Spanish travel blogs
}

\author{
Manuel Linares-Rufo 1,2, Laura Santos-Larrégola 2,3 ${ }^{2,3}$ Miguel Górgolas Hernández-de-Mora ${ }^{4}$ and
} José-Manuel Ramos-Rincón ${ }^{5^{*}}$

\begin{abstract}
Background: Europe has about 10,000 imported cases of malaria each year, or around 80 cases per 100,000 trips to endemic areas. Non-use of chemoprophylaxis in travellers remains the main reason for this. The proliferation of online travel blogs as a source of advice (sometimes the only one used) for preparing a trip to an endemic area may play a role in the decision to use chemoprophylaxis. The aim of this study was to analyse the information offered on malaria in the main travel blogs in English and Spanish.
\end{abstract}

Methods: Five hundred travel blogs in English and 100 in Spanish, considered highly relevant were analysed. The relevance were according to different metrics: (1) Alexa Rank; (2) social networks (RRSS) measuring the total followers of Facebook, Twitter, Instagram and YouTube; (3) number of monthly visits using the SEMrush tool; (4) domain authority; and (5) number of backlinks or incoming links using the SEMrush tool.

Results: Of the included travel blogs, $57 \%$ of those in English and 64\% of those in Spanish offered information on malaria, and 79 and $75 \%$, respectively, featured a discussion on malaria written as a blog post or in forum comments. Information on chemoprophylaxis was available in $56.1 \%$ of English-language blogs and $10.7 \%$ of Spanish-speaking blogs, while its side effects were discussed in 38.6 and $68.8 \%$, respectively $(p<0.001)$. Content analysis revealed that the information was usually insufficient, incomplete or, more seriously, inaccurate. In many cases, this could discourage users from taking appropriate preventive measures.

Conclusions: Travel blogs in English and Spanish provide low-quality information on malaria. The so-called "travel influencers" must communicate reliable, verified and quality information on malaria on their channels in a way that could contribute to reducing the burden of the disease in travellers.

Keywords: Malaria, Traveler, Tourist, Blog, Social Networks, Traveler Advice, Chemoprophylaxis, Prevention

\section{Background}

About 10,000 imported cases of malaria are reported in Europe each year, or about 80 for every 100,000 trips to endemic areas. The global incidence of the disease was estimated at 229,000,000 cases in 2019, of which more than 50\% occurred in Africa [1]. Frequent international travel combined with the inadequate use of

\footnotetext{
*Correspondence: jose.ramosr@umh.es

${ }^{5}$ Department of Medicine, Universidad Miguel Hernández de Elche, Alicante, Spain

Full list of author information is available at the end of the article
}

preventive measures in travellers result in a high number of imported malaria cases worldwide [2,3].

Despite the existence of official databases, the real burden of imported malaria in non-endemic countries is probably underestimated [4]. Prevalence estimates are subject to important limitations, as only surveys are available rather than the actual number of travellers by origin and destination. In the USA, the Centers for Disease Control and Prevention (CDC) reported 2161 confirmed imported malaria cases with onset of symptoms in 2017. In the European Union, the European Centre for Disease Prevention and Control (ECDC) reported 8641 original author(s) and the source, provide a link to the Creative Commons licence, and indicate if changes were made. The images or other third party material in this article are included in the article's Creative Commons licence, unless indicated otherwise in a credit line to the material. If material is not included in the article's Creative Commons licence and your intended use is not permitted by statutory regulation or exceeds the permitted use, you will need to obtain permission directly from the copyright holder. To view a copy of this licence, visit http://creativecommons.org/licenses/by/4.0/. The Creative Commons Public Domain Dedication waiver (http://creativeco mmons.org/publicdomain/zero/1.0/) applies to the data made available in this article, unless otherwise stated in a credit line to the data. 
malaria cases in 2019 [5]. Other countries such as Canada, Australia or the UK report quite similar numbers of cases per 1 million population [6]. In 2019, tourist travel increased in all regions of the world by $3.8 \%$ over the previous year, reaching 1.5 billion travellers globally. AsiaPacific saw growth of $4.6 \%$ and Africa, $4.2 \%$, higher than the global average [7].

The risk of imported malaria is known to be higher in travellers to Africa, especially migrants and people visiting friends and relatives (VFRs). There are many studies that indicate that chemoprophylaxis use is still insufficient in people with imported malaria cases, both in these high-risk groups as well as young people and travellers with a high educational level $[8,9]$.

The first source of information that the traveller can access is the official, "classic" route, that is, specific, timely advice offered by health professionals through specialized clinics [10]. However, informal sources should not be overlooked, as they complement professional advice and condition travellers' choices and attitudes with regard to how to act when travelling to a malaria-endemic country. Travel blogs in particular have proliferated across the web, offering a firsthand, layperson's account on different destinations. Thus, the objective of this study was to analyse the information offered on malaria in the main travel blogs in English and Spanish.

\section{Methods}

Six hundred travel blogs (500 in English and 100 in Spanish) with general content for travellers and accounts of trips to malaria-endemic countries were analysed. The blogs were selected based on different metrics assessing their relevance (Additional file; Table S1, Table S2 1), using the following external tools: (1) Alexa Rank (a Global Search Engine Optimization [SEO] positioning system; Amazon Company, USA; https://www.alexa. com/siteinfo); (2) social networks (RRSS) measuring the total followers of Facebook, Twitter, Instagram and YouTube), using Influencer Marketing Hub (https://influ encermarketinghub.com/), Fanpage Karma (https://www. fanpagekarma.com/) and Metricool (https://metricool. com); (3) number of monthly visits using the SEMrush tool (https://es.semrush.com/); (4) domain authority, using the MOZ tool (https://moz.com/free-seo-tools); and (5) the number of backlinks or incoming links using the SEMrush tool. Moreover, the monthly and annual visits/users for all the English and Spanish blogs selected using the tools available on the Alexa website were estimated.

The blog's own search engine was used to find content (text, video, or podcasts) that included the word "malaria". The quality of the information was examined according to the 10 yes/no questions shown in Table 1.

The differences between English- and Spanish-language blogs were determined using Pearson's chi-square test for categorical variables. Values were considered to be statistically significant when the $\mathrm{p}$ value was less than 0.05 . Statistical data analysis was performed using IBM SPSS Statistics for Windows, Version 25.0 (Armonk, NY: IBM Corp).

\section{Results}

Web traffic measurement tools show that collectively, the 600 blogs analysed have a reach of 92,400,000 unique visitors/month, for an incredible $1,108,800,000$ visitors per year. No information on malaria was available in $43 \%$ of the 500 English-language or in $36 \%$ of the 100 Spanish-language blogs, even though they were pages that offered recommendations for visiting endemic countries. On the other hand, about 95\% of Spanish blogs did

Table 1 Quality items from Spanish- and English-language travel blogs

\begin{tabular}{|c|c|c|c|c|c|}
\hline \multirow[t]{2}{*}{ Quality items } & \multicolumn{2}{|l|}{ English } & \multicolumn{2}{|c|}{ Spanish } & \multirow[t]{2}{*}{ p value } \\
\hline & $\mathrm{n} / \mathrm{N}$ & $\%$ & $\mathrm{n} / \mathrm{N}$ & $\%$ & \\
\hline Does the blog offer information on malaria? & $285 / 500$ & 57 & $64 / 100$ & $64 \%$ & 0.19 \\
\hline Is there a discussion on malaria in the forum or comments section? & $225 / 285$ & 79 & $48 / 64$ & 75 & 0.49 \\
\hline Does the blog contain information on the side effects of chemoprophylaxis? & $110 / 285$ & 38.6 & $44 / 64$ & 68.8 & $<0.001$ \\
\hline Is the information provided up-to-date? ${ }^{a}$ & $60 / 285$ & 21.1 & $22 / 64$ & 34.4 & 0.023 \\
\hline Does the blog offer links to official/specialized travel medicine websites? & $45 / 285$ & 15.8 & $10 / 64$ & 15.6 & $>0.99$ \\
\hline $\begin{array}{l}\text { Does the blog advise non-certified preventive products against malaria or whose effec- } \\
\text { tiveness is questionable? }\end{array}$ & $15 / 285$ & 5.3 & $10 / 64$ & 15.6 & 0.007 \\
\hline Does the blog have adequate information on chemoprophylaxis? & $160 / 285$ & 56.1 & $7 / 64$ & 10.9 & $<0.001$ \\
\hline Is the information that the blog provides referenced? & $35 / 285$ & 12.3 & $4 / 64$ & 6.3 & 0.12 \\
\hline Does the blog provide correct information on standby emergency treatment? & $20 / 285$ & 7.0 & $2 / 64$ & 3.1 & 0.28 \\
\hline Was the information on malaria generated or reviewed by a healthcare professional? & $10 / 285$ & 3.5 & $2 / 64$ & 3.1 & $>0.99$ \\
\hline
\end{tabular}

${ }^{a}$ Reviewed in the last year. In bold, statistically significant differences 
offer advertising or advertising content for travel health insurance.

Of the blogs that contained information on malaria (English $\mathrm{n}=285$ and Spanish $\mathrm{n}=64$ ), 79 and $75 \%$, respectively, mentioned malaria in the forum or comments section. Information on chemoprophylaxis was available in 56.1\% of English-language blogs and 10.7\% of Spanish-speaking blogs, while its side effects were discussed in 38.6 and $68.8 \%$, respectively $(\mathrm{p}<0.001)$. Only 21.1 and $34.4 \%(\mathrm{p}=0.023)$ of the blog posts presented up-to-date information (reviewed in the previous year) (Table 1 ).

Only $15.8 \%$ of the English- and $15.6 \%$ of the Spanishlanguage blogs provided links to official/specialized websites (e.g. international vaccination centers, Ministry of Health, other specialized websites dedicated to travel medicine). A minority (English 5.3\%, Spanish $15.6 \%, \mathrm{p}=0.007$ ) advised uncertified preventive products against malaria or products of dubious effectiveness, such as garlic, onion, vitamin B, bracelets, nitrous oxide, various cosmetics, anti-mosquito candles, or electrical/ultrasonic devices to repel mosquitoes. Few blogs (English 12.3\%, Spanish 6.3\%) included references for the information presented. Only 7.0 and $3.1 \%$ of the blogs, respectively, provided correct information about self-treatment, while healthcare professionals generated or reviewed the information in just 3.5 and $3.1 \%$ of the blogs (Table 1).

In the qualitative analysis uncovered several important misconceptions in the blogs (Table 2), reflecting the main pitfalls found in the analysis of malaria chemoprophylaxis. Some key points have been detected which could inform interventions to improve advice.

\section{Discussion}

This study showed the low quality of information about malaria published on travel blogs in English and Spanish. The content was generally insufficient, incomplete or, worse, inaccurate, with the result being that the users may be discouraged from taking adequate preventive measures. The scientific quality of these blogs may be related to a greater number and severity of imported malaria cases, as travellers may follow advice without an adequate scientific basis when making decisions about malaria prevention.

Efforts in malaria prevention in other environments, such as travel agents or specific groups of travellers, are well known [11]. However, to date these initiatives have been practically nonexistent in the field of travel blogs, despite the current context of "infoxication" or online fake news [12].

Sometimes travellers' perceptions of malaria risks are unrealistic. Travel blogs should thus correct misperceptions (such as believing that curing malaria is easier than taking prophylaxis or that travellers visiting relatives have some level of innate immunity). Certain "filter criteria" could also be applied, allowing the user to evaluate the information obtained for themselves. However, in other, so-called "mainstream" media, such as newspapers, radio or television, the information presented may also be erroneous, incomplete or biased, but that is not cause for it

Table 2 Patterns of misconceptions around chemoprophylaxis for malaria, as identified in qualitative analysis of travel blogs

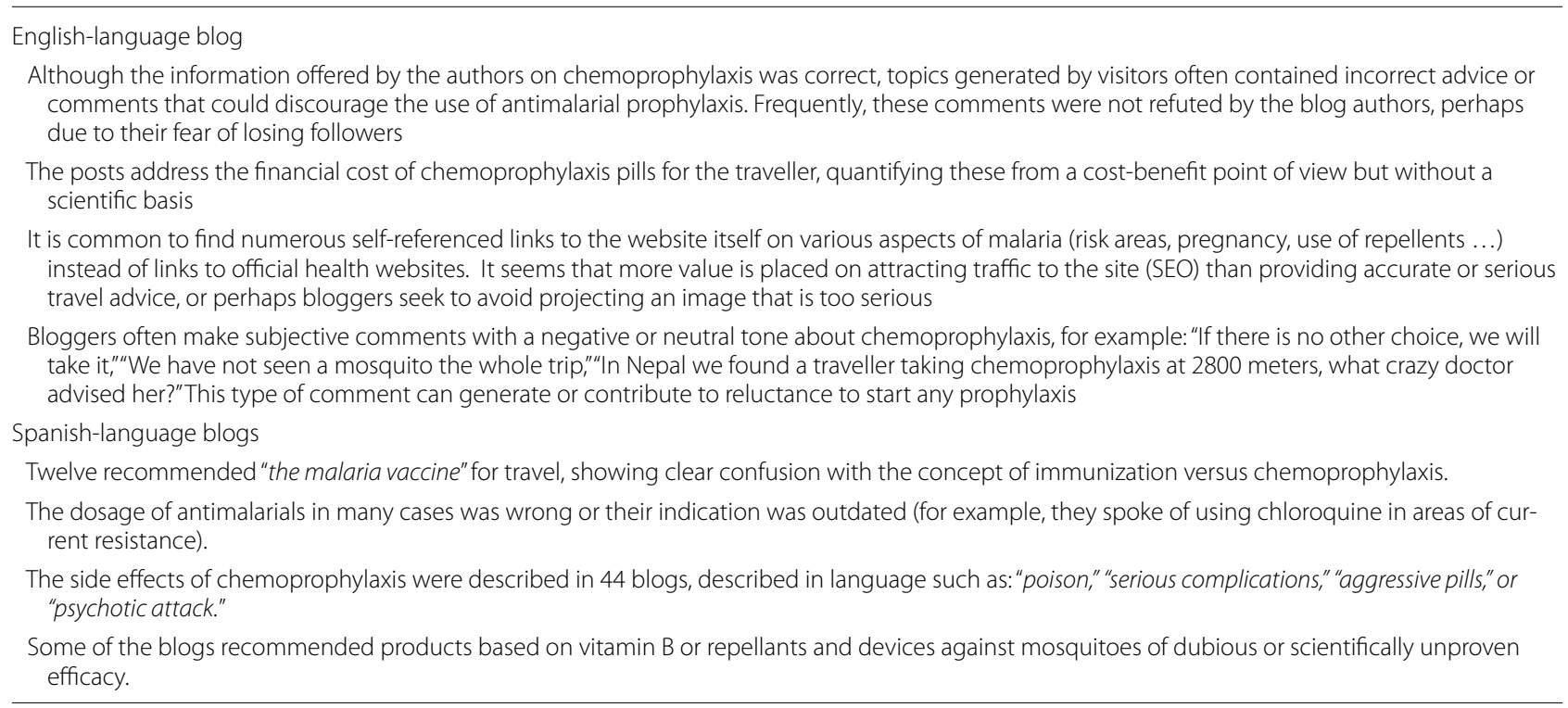


to be withdrawn. Rather, the user must apply their own personal judgment.

The adoption of codes of conduct and ethics, such as HONcode [13], could be a more reliable way to favour the generation and dissemination of high-quality, accurate information. Since a significant proportion of people have low health literacy and difficulties accessing information, many audiences may find it challenging to assess the quality of the information and apply it to their own circumstances [14]. The so-called "travel influencers" must, therefore, communicate reliable, verified and high-quality information on malaria in a way that could contribute to reducing the burden of disease in travellers.

Introducing a code of conduct for sensitive information provided by these sites is further justified by the fact that malaria prevention is just a small drop in the ocean of popular medical communication. Indeed, the larger problem is so huge that it is really hard addressing this single aspect alone, or even medical travel advice in general. Good initiatives exist, including the HONcode, but most people are not aware of them [15]. Moreover, many prestigious medical and academic sites do not adhere to HONcode, which can by no means be enforced. However, this work is a first step in an open and relevant line of work [16].

The main strength of the study resides in the fact that it opens the door to innovative interventions to improve malaria prophylaxis. It also touches on a much wider topic of interest than the specific focus of the study, namely the ability to refer blog readers to quality information to improve the training of travellers.

However, the results of this study should be interpreted in light of the study's limitations. First of all, the study was performed in only English and Spanish blogs, which may be different from blogs in other languages. Secondly, the study did not differentiate between the country where the bloggers were based. Third, the criteria used for measuring quality was based on researchers' subjective experience.

In conclusion, travel blogs written in English and Spanish often provide low-quality information on malaria. The contents offered were generally insufficient, incomplete or, worse, inaccurate. Further qualitative studies are necessary to analyse the quality of information on malaria in online media.

\section{Supplementary Information}

The online version contains supplementary material available at https://doi. org/10.1186/s12936-021-03864-2.

Additional file 1: Table S1. 500 English travel blogs analyzed by alphabetic order. Table S2. 100 Spanish travel blogs analyzed by alphabetic order.
Acknowledgements

We many thank the contributions and ideas of all the travel bloggers consulted.

\section{Authors' contributions}

$M L R$, and LSL collected the data, analysed the data and wrote the manuscript; MGH, and JMRR analysed the data and revised and edited the manuscript. All authors read and approved the final manuscript.

\section{Funding}

The authors received no specific funding for this work.

\section{Availability of data and materials}

J.M.R.R. has full access to and is the guarantor for the data. The datasets generated are available from the corresponding author on reasonable request.

\section{Declarations}

Ethics approval and consent to participate

According to the Spanish law, approval by an ethics committee was not necessary for this study.

\section{Consent for publication}

Not applicable.

\section{Competing interests}

The authors declare that they have no conflict of interest.

\section{Author details}

${ }^{1}$ Microbiology Service, Hospital Universitario Príncipe de Asturias, Alcalá de Henares, Madrid, Spain. ${ }^{2}$ Foundation iO, Madrid, Spain. ${ }^{3}$ Buenos Aires Health Centre, Madrid, Spain. ${ }^{4}$ Department of Medicine, Universidad Autónoma de Madrid, Madrid, Spain. ${ }^{5}$ Department of Medicine, Universidad Miguel Hernández de Elche, Alicante, Spain.

Received: 22 May 2021 Accepted: 23 July 2021

Published online: 16 August 2021

\section{References}

1. WHO. World malaria report 2020. Geneva: World Health Organization; 2020. https://www.who.int/publications/i/item/9789240015791. Accessed 1 Feb 2021.

2. Mace KE, Lucchi NW, Tan KR. Malaria surveillance-United States, 2017. MMWR Surveill Summ. 2021;70:1-35.

3. Kendjo E, Houzé S, Mouri O, Taieb A, Gay F, Jauréguiberry S, et al. Epidemiologic trends in malaria incidence among travelers returning to Metropolitan France, 1996-2016. JAMA Netw Open. 2019;2:e191691.

4. Herrador Z, Fernández-Martinez B, Quesada-Cubo V, Diaz-Garcia O, Cano R, Benito A, Gómez-Barroso D. Imported cases of malaria in Spain: observational study using nationally reported statistics and surveillance data, 2002-2015. Malar J. 2019;18:230.

5. European Centre for Disease Prevention and Control. Introduction to the annual epidemiological report. Stockholm: ECDC; 2020. https://www. ecdc.europa.eu/en/publications-data/malaria-annual-epidemiologicalreport-2018Accessed 1 Feb 2021.

6. O'Brien SF, Delage G, Seed CR, Pillonel J, Fabra CC, Davison K, et al. The epidemiology of imported malaria and transfusion policy in 5 nonendemic countries. Transfus Med Rev. 2015;29:162-71.

7. World Tourism Organization (UNWTO). https://www.unwto.org/es/ unwto-tourism-dashboard. Accesessed 19 July 2021.

8. Hoefnagel JGM, Massar K, Hautvast JLA. Non-adherence to malaria prophylaxis: the influence of travel-related and psychosocial factors. J Infect Public Health. 2020;13:532-7.

9. Ahluwalia J, Brooks SK, Weinman J, Rubin GJ. A systematic review of factors affecting adherence to malaria chemoprophylaxis amongst travelers from non-endemic countries. Malar J. 2020;19:16.

10. Herman J, Patel D. Advising the traveller. Medicine. 2018;46:59-65. 
11. Bazaz R, Green E, Green ST. Quality of malaria information provided on Internet travel operator websites. Travel Med Infect Dis. 2010;8:285-91.

12. Di Domenico G, Sit J, Ishizaka A, Nunan D. Fake news, social media and marketing: a systematic review. J Bus Res. 2021;124:329-41.

13. Health On the Net Foundation (HON Foundation). The HON code of conduct for medical and health Web sites (HONcode) [monograph on the Internet]. Geneva: HON Foundation; 2017. http://bit.ly/2PpHUcj. Accessed 1 Feb 2021.

14. Charow R, Snow M, Fathima S, Giuliani ME, McEwan K, Winegust J, Papadakos J. Evaluation of the scope, quality, and health literacy demand of Internet-based anal cancer information. J Med Libr Assoc. 2019;107:527-37.
15. Wrigley Kelly NE, Murray KE, McCarthy C, O'Shea DB. An objective analysis of quality and readability of online information on COVID-19. Health Technol (Berl). 2021. https://doi.org/10.1007/s12553-021-00574-2.

16. Agar A, Sahin A. Kyphosis-related information on the internet is the quality, content and readability sufficient for the patients? Glob Spine J. 2021;12:21925682211015956.

\section{Publisher's Note}

Springer Nature remains neutral with regard to jurisdictional claims in published maps and institutional affiliations.
Ready to submit your research? Choose BMC and benefit from:

- fast, convenient online submission

- thorough peer review by experienced researchers in your field

- rapid publication on acceptance

- support for research data, including large and complex data types

- gold Open Access which fosters wider collaboration and increased citations

- maximum visibility for your research: over $100 \mathrm{M}$ website views per year

At BMC, research is always in progress.

Learn more biomedcentral.com/submissions 